ported by Drevets et al. Taken together, the classic studies and the new results of Drevets et al. imply that suppression of competing stimuli is a central element in many aspects of preparing to receive a stimulus.

Although it seems clear that the general influence of attention in improving the perceptibility of stimuli is general to all sensory modalities, perhaps the exquisite localization of suppression found by Drevets et al. is due to use of somatosensory stimuli in their experiments. The authors describe the possible gating system that could lead to the decrease in neuronal activity in somatosensory areas surrounding the target location.

The evidence favouring a local influence of attention within the brain is of great importance for understanding voluntary control over mental processes. To go further will require knowledge of how voluntary control is exercised within local brain networks, and obtaining this information will require connecting neuroimaging with methods designed to examine local electrical activity, millisecond by millisecond, during acts of attention. Research to that end is under way $^{11}$.

Michael Posner is in the Institute of Cognitive and Decision Sciences, University of Oregon, Eugene, Oregon 97403, USA.

\footnotetext{
1. Kahneman, D. Attention and Effort (Prentice Hall, Englewood Cliffs, New Jersey, 1973).

Drevets, W. C. et al. Nature 373, 249-252(1995)

3. Corbetta M etal Jeurosci 11 2383-2402 (1991)

5. Fox, P. T. et al. Nature 323, 806-809 (1986)

6. Heinze, H. J. et al. Nature 372, 543-546 (1994).

. Raichle, M. E. in Handbook of Physiology Vol. V. Pt 2 (ed. Plum, F.) 643-674 (Oxford Univ. Press, 1987).

8. Luck, S. Curr. Opin. Neurabiol. 4, 183-188 (1994)

9. Moran, J. \& Desimone, R. Science 229, 782-784 (1985).

10. Posner, M. I. \& Petersen, S. E. A. Rev. Neurosci. 13. 25-42(1990)

11. Wood, C. C. Hum. Brain Map 1, iil-vi (1994).
}

actions that pervade transcription control - hence the interest in the structure of the Fos-Jun heterodimer.

The leucine zipper is the simplest of dimerization interfaces, yet it can mediate highly selective and avid protein associations. It was first identified as a sequence motif in C/EBP (ref. 5), and has been recognized as an interaction surface in many transcription factors. Glover and Harrison's Fos-Jun crystal structure largely confirms previous predictions of the molecular basis of dimerization selectivity ${ }^{6}$. The hydrophobic coiled-coil interface is elaborated by interactions between adjacent residues. Interhelical salt bridges between residues flanking the hydrophobic interface are particularly important in determining dimerization specificity. Residues of opposite charge at these positions (as in the Fos-Jun heterodimer) would tend to stabilize the zipper, whereas residues of like charge (as in a hypothetical Fos homodimer) would tend to destabilize it. The interactions affecting dimer stability involve a large number of residues that differ for each of the many possible dimer complexes - at last count more than a hundred different dimers could be assembled from the known subunits of this extended family, so it will be a formidable task to derive the general rules governing dimerization specificity.

Leucine zipper dimerization serves to juxtapose adjacent regions of each protein rich in basic amino-acid residues that undergo a conformational change upon binding to $\mathrm{DNA}^{7,8}$. Although the resulting $\alpha$-helical DNA-contact interface is now understood in great detail, the nature of the conformational change and its part in DNA recognition are less clear. Fos and Jun make essentially identical contacts with the AP-1 site, and similar to those in the GCN4 crystal structures ${ }^{9,10}$. Most of the amino-acid residues that make direct contacts with nucleotide bases in the FosJun and GCN4 structures are conserved among most bZIP family proteins, even sarcoma virus ${ }^{2}$ and the avian sarcoma virus 17 (ref. 3). Both are derived from
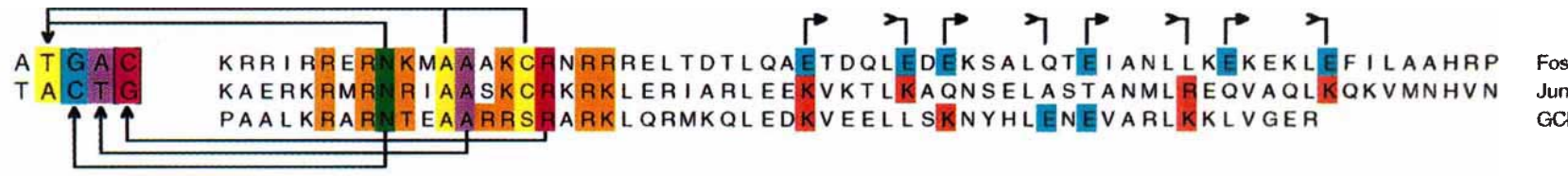
Jun GCN4

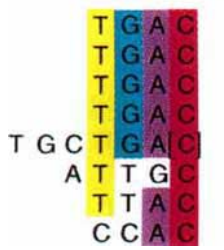

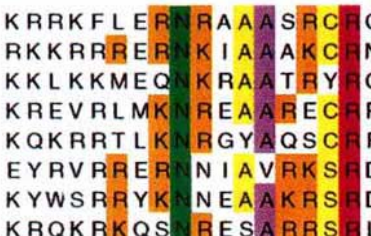
QKRKVWVQSLEKKA
NKKKEKTECLQKE
QKKRAEQEALTGE
RKKKEYVKCLENB
FKRVQQRHVLESEK
DKAKQRNVETQQK
DARRLKENQI SVRA
LRKQAECEQLQQA AEDLSSLNGQLQSEVTLLFNEVAQLKQLLLAHKD SEKLESVNAELKAQ I EEL KNEKQHL I YMLNLHRP CKEL KKNEA LKERADSLARE I QYLKDL I EEVRK VAVLENQNKTL I EELKALKDLYCHKSD KNQLLQQVEHLKOE I SRLVRERDAYKEKYEKLVS VLELTSDNDRL RKAVEQLSRELDTLAGIFRQLPE AAFLEKENALLRQEVVAVRQELSHYAAVLSRYQA KRQKRKQSNRESARASBLRKQAECEQLQQAVESLSNENQSLADELQRLSSECDKLKSENNSIQD

Conservation of residues determining Fos-Jun DNA-binding and dimerization specificity. The DNA-binding half-sites and amino-acid sequences of representative members of several bZIP protein subfamilies are listed. The amino-acid residues that make base contacts in Fos-Jun and GCN4 are shown in the same colours as the bases that they contact. Green amino acids contact both yellow and blue bases.
Amino-acid residues that make phosphate backbone contacts are in orange. Contact residues that are conserved in other bZIP proteins are indicated. Brackets around bases indicate that they are present in only one of the two half-sites. Charged residues at positions in the leucine zipper that are important for dimerization specificity are coloured red for basic and blue for acidic. 
those with a distinct DNA-binding specificity. Hence they may have a structural function in the basic region, as well as making direct contacts to bases in the AP-1 site. In fact, the residues that make contacts with the phosphodiester backbone are more frequently substituted in proteins that bind distinct DNA sequences, meaning that these phosphate contacts might be involved in DNA sequence recognition. However, there are some bZIP protein subfamilies in which substitutions of amino-acid residues that make base contacts at the AP-1 site correlate with changes in DNA-binding specificity (see figure).

Other changes in DNA-binding specificity and some results of mutational analyses cannot be easily accounted for. Many bZIP proteins recognize base pairs outside the central heptanucleotide core, and amino acids outside the region crystallized by Glover and Harrison also influence DNA-binding affinity and specificity. A particularly striking example is the Maf/Nrl subfamily, in which an ancillary DNA-binding region on the aminoterminal side of the basic region is required for specific recognition of a site that includes a TGC recognition element flanking the central core ${ }^{11,12}$. Thus, the bZIP recognition motif can be embellished by other specificity-determining regions, allowing more sophisticated discrimination of DNA target sequences.

The structure of the DNA helix in the Fos-Jun-DNA crystal is much like that of straight B-DNA. This contrasts with the conclusions of other studies, employing conformationally sensitive gel electrophoresis, suggesting that Fos and Jun cause DNA bends of opposite orientations ${ }^{13}$. These DNA bends were caused in part by regions of the proteins located outside the minimal bZIP regions used for crystallization. Although the specific residues that caused DNA bending by Fos and Jun have not been identified, a comparison of the DNA-bending properties of many bZIP family proteins implicates amino acids immediately amino-terminal of the basic region. The net charge of this region is positive in proteins that bend DNA towards the basic region, but negative in proteins that bend DNA away from the basic region. Recently, neutralization of phosphodiester charges on one face of a DNA helix was shown to cause DNA bending ${ }^{14}$. Such electrostatic interactions could mediate DNA bending by bZIP family proteins. These forces could be shielded in the presence of the high concentrations of multivalent cations used in the crystallization process. Crystal packing forces can also affect DNA structure, because the oligonucleotides in adjacent cells often stack in an arrangement that favours straight DNA.

The crystal analysed by Glover and Harrison provided an unexpected bonus
- two structures that differ in the orientation in which heterodimers bind to the asymmetric AP-1 site. The DNA contacts in the two structures are similar, except that Fos interacts with the asymmetric central base pair in one complex, Jun in the other. This orientation-independence of Fos-Jun binding to the AP-1 site has implications for transcription regulation. The asymmetry generated by heterodimer formation provides distinct surfaces for interactions with other transcription factors. Many promoter elements work in an orientation-dependent manner, perhaps as a consequence of such asymmetric contact interfaces. The orientation of Fos-Jun heterodimers may be determined by interactions with other transcription factors or by contacts with components of the general initiation complex. Indeed, Fos and Jun can function in association with other transcription factors, such as in the NFAT complex which is a target of the immunosuppressive drugs cyclosporin A and FK506 (ref. 15).

Although it is aesthetically pleasing, the simple picture of the Fos-Jun bZIP core does not explain the biological specificity of these molecules. Many mechanisms are probably involved in targeting a specific leucine zipper dimer to the right response element at the right time, including posttranslational modification and interactions with other transcription factors and associations with basal factors and TAFs. Nevertheless, the simplicity of the bZIP structure encourages the hope that the bewildering complexity of transcription regulation will in time be resolved into a manageable number of comprehensible components.

Tom Kerppola is in the Howard Hughes Medical Institute, Department of Biological Chemistry, University of Michigan Medical School, Ann Arbor, Michigan 48109, USA. Tom Curran is at the Roche Institute of Molecular Biology, Roche Research Center, Nutley, New Jersey 07110, USA.

1. Glover, J. N. M. \& Harrison, S. C. Nature 373, 257-261 (1995)

. Curran, T. \& Teich, N. M. J. Virol. 42, 114-122 (1982).

3. Maki, Y Bos, $T$, J Davis, C Starbuck, M \& Vogt P. K. Proc natn. Acad. Sci. U.S.A. 84. $2848-2852$ (1987).

4. Curran, T. \& Franza, B. R. Jr Cell 55, 395-397 (1988).

5. Landschultz, W. H., Johnson, P. F. \& McKnight, S. L. Science 240, 1759-1764 (1988)

6. O'Shea, E. K., Rutkowski, R. \& Kim, P. S. Ce//68, 699-708 (1992)

Patel, L. et al. Nature 347, 572-575(1990)

7. Patel, L. et al. Nature 347, 572-575(1990),

9. Ellenberger, T. E., Brandl, C. J., Struhl, K. \& Harrison Ellenberger, T. E., Brandl, C. J., Str
S.C. Cell 71, 1223-1237 (1992).

10. König, P. \& Richard, T. J. J. molec. Biol. 233, 139-154 (1993).

11. Kataoka, K., Noda, M. \& Nishizawa, M. Molec. CellBiol 14, 700-712 (1994)

12. Kerppola, T. K. \& Curran, T. Oncogene $9,3149-3158$ (1994).

13. Kerppoia, T. K. \& Curran, T. Science 254, 1210-1214 (1991).

14. Strauss, J. K. \& Maher, L. J. III Science 266, 1829-1834 (1994).

15. McCaffrey, P. etal. Science 262, 750-754 (1993).

\section{Instant sculpture}

THE atomic bomb works by implosive forming. A hollow, shaped charge of high explosive, detonated at many points under exact time control, crushes a plutonium core to criticality. The first bombs merely compressed a spherical core symmetrically. Bomb physicists these days can compute the initial shape and timings needed for highly subtle asymmetric modes of implosive compression.

This process, says Daedalus, deserves wider use. Alone among forming technologies, it could bend and cold. form brittle substances such as glass and ceramics. The vast pressure of the surrounding explosion would put the workpiece completely into compression. Cracking would be inhibited, and it would yield by plastic flow. Even better, two or more surfaces forced together would pressure-weld into a single monolithic block. Implosive forming could be a neat way of shaping intractable, infusible, advanced ceramics into pistons and turbine blades. Yet Daedalus has a different plan. He wants to use the technique on natural hard materials, such as bones and teeth.

He points out that the elephant is threatened with extinction merely because its ivory tusks are large, monolithic chunks of dentine. Dentine is only apatite bonded with a little protein; yet the subtle microstructure of elephant ivory defies imitation. Its toughness and permanence make it one of the most desirable of craft materials. By implosive forming, it should be possible to take cow or sheep dentine as powder or small chunks, and pressure-weld it instantly into cheap monolithic blocks of artificial ivory. With sufficient computational cunning, the implosion could even shape it, giving anything from a billiard ball or a piano key to a rococo statuette with scrolls and cherubs. Now that the Cold War is over, nuclear weapons experts are desperate to find peaceful uses for their knowledge. By developing the implosive forming of animal dentine, they could flood the market with cheap artificial ivory and objects formed from it, thus taking the heat off the beleaguered elephant. This new and profitable business would also redeem their sinful past, allowing them to bask at last in ecological rectitude.

Implosive forming would work on bone as well as dentine, and even on marble, jade and similar minerals. Chunks of different materials could be pressurewelded into composite structures, and mixed powders could be formed into novel 'alloys'. A whole new family of composite materials could implode onto the technical scene. David Jones 